\title{
AÇÃO FISCALIZATÓRIA E ADEQUAÇÃO DA INDICAÇÃO, COMÉRCIO E USO DE AGROTÓXICOS POR AGRICULTORES DA FRONTEIRA OESTE DO RIO GRANDE DO SUL
}

\author{
Juliano Goulart Ritter ${ }^{l}$, Fernando Felisberto da Silva ${ }^{2}$, Alexandre Russini ${ }^{2 *}$ \\ 1 Secretaria da Agricultura Pecuária, Inspetoria de Defesa Agropecuária, 97650-000, Itaqui, Brasil. \\ 2 Campus Itaqui, Universidade Federal do Pampa, 97650-000, Itaqui, Brasil.
}

*E-mail: alexandrerussini@unipampa.edu.br

\section{RESUMO}

A falta de fiscalização no uso de agrotóxicos junto aos agricultores é fator agravante para o cumprimento da legislação ambiental. O objetivo deste trabalho foi avaliar a validade da ação fiscalizatória no cumprimento da legislação referente ao uso de agrotóxicos por parte dos agricultores da Fronteira Oeste do Rio Grande do Sul e suas consequências à saúde e o ambiente. Foram fiscalizadas 80 propriedades rurais em duas safras agrícolas, antes e após as orientações oficiais da fiscalização estadual. Avaliaram-se os depósitos de agrotóxicos, disponibilidade e uso do EPI, receitas agronômicas, devolução de embalagens vazias e uso de agrotóxicos, conforme as normas e procedimentos legais. As avaliações foram agrupadas em 14 possíveis infrações à legislação de agrotóxicos. Verificou-se um aumento em oito tipos de infrações e em quatro, houve redução. As infrações mais comuns foram a utilização de agrotóxico em desacordo com a receita, o armazenamento irregular, o não fornecimento do EPI, a não destinação correta das embalagens vazias e a não apresentação das receitas agronômicas. A presença da fiscalização auxiliou diretamente na utilização de agrotóxicos em conformidade com a receita.

Palavras-chave: Receita agronômica. Lei dos agrotóxicos. Fiscalização agropecuária. Risco à saúde.

\section{Introdução}

A utilização de agrotóxicos traz vantagens aos produtores no controle de pragas e consequentemente na produtividade de suas atividades agrícolas, porém deve haver controle sobre seu uso e rejeitos, a fim de reduzir os riscos de contaminação ambiental e impactos à saúde humana. Nos últimos 12 anos, o mercado brasileiro de agrotóxicos cresceu $190 \%$, posicionando o País como o maior consumidor desde 2008 [1]. Parte dos produtores rurais está ciente dos riscos da utilização de agrotóxicos, porém continuam fazendo o uso por necessidade de sobrevivência financeira, pois dependem deles para garantir a sanidade da lavoura [2].

A falta de fiscalização no acompanhamento técnico e no controle de agrotóxicos faz com que a tomada de decisão do agricultor seja baseada apenas na produtividade, sem levar em conta fatores relativos à saúde e ao meio ambiente [3]. O "uso seguro" de agrotóxicos, termo criado pelas indústrias, recai sobre a incapacidade do Estado brasileiro em fiscalizar e controlar as práticas de trabalho em todos os estabelecimentos rurais, assim como garantir treinamento a cada trabalhador rural que manipule estas substâncias [4].

A partir da Lei Federal 7802/89, denominada Lei dos Agrotóxicos, o receituário agronômico passou a ser exigido para a comercialização de agrotóxicos, sendo que a referida lei atualmente é regulamentada pelo Decreto Federal 4074/02. Segundo a legislação brasileira, a venda de agrotóxicos deve ser precedida da emissão da receita agronômica, com a finalidade de contribuir para o desenvolvimento da produção, minimizando os possíveis riscos à saúde humana e ao meio ambiente [5].

A região da Fronteira Oeste do Rio Grande do Sul caracteriza-se pelo monocultivo de arroz irrigado e, historicamente, esteve às margens da fiscalização efetiva em função da falta de profissionais para desempenho das atividades de fiscalização. Recentemente, fiscais estaduais foram lotados na região com o objetivo de fiscalizar o comércio e uso de agrotóxicos, entre outras atividades. Diante desse cenário e considerando a escassez deste tipo de estudo, criou-se uma situação na qual se pode avaliar a efetividade da ação fiscalizatória em anos sem e com a fiscalização.

O objetivo do presente trabalho foi avaliar a conformidade legal das receitas agronômicas emitidas pelos responsáveis técnicos de empresas comerciantes de agrotóxicos e avaliar a validade da ação fiscalizatória no cumprimento da legislação referente ao uso de agrotóxicos por parte dos agricultores da Fronteira Oeste do Rio Grande do Sul. 


\section{Metodologia}

O presente estudo foi realizado na Fronteira Oeste do Rio Grande do Sul, nos municípios de Itaqui (2907'19,1'’S e $56^{\circ} 33^{\prime} 22,3^{\prime \prime} \mathrm{W}$, coordenadas da sede municipal), Uruguaiana

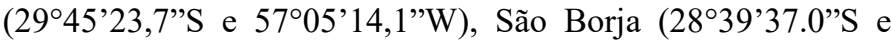
$\left.56^{\circ} 00^{\prime} 29,0^{\prime \prime} \mathrm{W}\right)$, Maçambará $\left(29^{\circ} 08^{\prime} 56.2^{\prime} \mathrm{S}\right.$ e $\left.56^{\circ} 03^{\prime} 51,0^{\prime \prime} \mathrm{W}\right)$ e Barra do Quaraí $\left(30^{\circ} 12^{\prime} 37,4^{\prime \prime} \mathrm{S}\right.$ e $\left.57^{\circ} 33^{\prime} 21,0^{\prime \prime} \mathrm{W}\right)$, entre 2014 e 2016, abrangendo 80 propriedades rurais. As propriedades foram escolhidas, nos diferentes municípios da região, pelo critério de proximidade e acessibilidade em relação à sede regional da fiscalização estadual em Itaqui. Os dados utilizados se referem à fiscalização de uso de agrotóxicos, relacionadas à Lei Federal 7802/89, Decreto Federal 4074/02 e Norma ABNT NBR 9843/2013 [6]. Esta fiscalização foi realizada pela Secretaria da Agricultura, Pecuária e Irrigação (SEAPI) do Estado do Rio Grande do Sul, sendo tais dados extraídos dos termos de fiscalização e autos de infração emitidos pelos fiscais no período.

O trabalho foi realizado em duas safras agrícolas (2014/15 e 2015/16), sendo que em cada uma das safras, foram fiscalizadas as propriedades rurais e os responsáveis técnicos das revendas de agrotóxicos registradas para comercialização de agrotóxicos na SEAPI. A safra 2014/15 foi a primeira safra inspecionada pelos fiscais estaduais agropecuários lotados nos municípios de Uruguaiana e Itaqui. Nessa safra, empregou-se como método a orientação aos agricultores, pois houve o registro da infração, porém sem a autuação, a qual ficou condicionada a uma segunda visita caso a infração permanecesse. Por sua vez, na segunda safra foi efetuada a fiscalização com aplicação de penalidades pelo descumprimento da legislação. Os responsáveis técnicos foram fiscalizados nas revendas, mediante conferência das receitas agronômicas emitidas, além da verificação das receitas destinadas aos produtores, entregues por conta da fiscalização realizada na propriedade rural. Ainda, a respeito da documentação solicitada, verificaram-se junto ao produtor as notas fiscais e receitas agronômicas dos agrotóxicos adquiridos e utilizados na safra corrente e dos agrotóxicos armazenados no depósito da propriedade, além de comprovantes de devolução de embalagens vazias de agrotóxicos e guias de aplicações aéreas de agrotóxicos.

Os dados foram agrupados por safra, 2014/15 e 2015/16, sendo comparados, buscando-se identificar melhoria em relação ao cumprimento da legislação de agrotóxicos e afins e a consequente redução do número de infrações, por meio das ações de conscientização prévia e fiscalização posterior.

As infrações relacionadas à emissão de receitas agronômicas, retiradas dos manuais de fiscalização da SEAPI, foram as seguintes: 1. prescrever receita agronômica com diagnóstico falso (cultura inexistente); 2. prescrever receita agronômica com diagnóstico impossível; 3. prescrever receita agronômica de maneira errada, genérica, displicente ou indevida; 4. deixar a receita agronômica assinada e sem preenchimento do seu conteúdo, sob responsabilidade do estabelecimento comercial. Já as infrações relacionadas ao uso de agrotóxicos, diretamente aos agricultores, foram: 1. causar embaraço à fiscalização de agrotóxicos e afins, de maneira a impedir a ação fiscal; 2. usuário de agrotóxicos e afins que proceder em desacordo com as recomendações do fabricante e/ou da receita agronômica; 3. armazenar ou depositar agrotóxicos e afins, em propriedade rural, em desacordo com a legislação vigente e NBR $n^{\circ} 9.843 / 2013$ [6] 4. não destinar adequadamente as embalagens vazias de agrotóxicos e afins ou reutilizá-las; 5. não manter à disposição da fiscalização o comprovante de devolução das embalagens vazias de agrotóxicos e afins pelo prazo de, no mínimo, 01 (um) ano após a devolução das embalagens; 6. empregador que deixar de fornecer o Equipamento de Proteção Individual (EPI) ao trabalhador ou não fizer a manutenção do EPI; 7. aplicador de agrotóxicos e afins que deixar de utilizar os equipamentos de proteção individual, ou que usá-lo incompleto, no preparo da calda ou da aplicação; 8. manipular, importar, comercializar e utilizar agrotóxicos e afins não registrados no MAPA (ilegais e banidos); 9. utilização de agrotóxicos e afins não cadastrados na FEPAM, proibidos ou com restrição de uso no Estado do Rio Grande do Sul; 10. agricultor que não prestar informações ou não proceder a entrega de documentos nos prazos estabelecidos pela SEAPI, a fim de impedir as ações de fiscalização e a adoção das medidas que se fizerem necessárias; 11. não apresentar as receitas agronômicas referentes aos agrotóxicos e afins adquiridos; 12. causar danos ao meio ambiente, em função do descumprimento do disposto na legislação de agrotóxicos e afins; 13. dar outra destinação a agrotóxicos e afins apreendidos ou com o uso suspenso pela fiscalização da SEAPI, sem a devida autorização; 14. desobediência às determinações do órgão competente - SEAPI. Tais procedimentos fiscalizatórios encontram-se descritos no Manual de Procedimentos para Fiscalização do Uso, Comércio e Prestação de Serviços na Aplicação de Agrotóxicos e Afins, e do Comércio de Sementes e Mudas, referente ao Estado do Rio Grande do Sul, 2013.

A fim de comparar as duas safras avaliadas, realizouse o teste binomial, não paramétrico, para duas amostras independentes para dados categóricos.

\section{Resultados e discussões}

$\mathrm{Na}$ região do estudo registrou-se 30 responsáveis técnicos emitindo receitas agronômicas nas 27 revendas registradas na SEAPI. Na safra 2014/15 foram autuados $70 \%$ dos responsáveis técnicos, devido a irregularidades na emissão de receitas agronômicas. Na safra seguinte, foram autuados 
23,3\% dos responsáveis técnicos demonstrando que o fato de haver fiscalização frequente na primeira safra, reduziu $o$ número de infrações em 70,8\% (Tabela 1).

Tabela 1. Infrações na emissão de receitas agronômicas apuradas nas safras 2014/15 e 2015/16.

\begin{tabular}{lcc}
\hline \multicolumn{1}{c}{ Infração Anotada } & Safra 2014/15 & Safra 2015/16 \\
\hline Cultura Inexistente & 19 & 2 \\
Diagnóstico Impossível & 0 & 5 \\
Receita Errada ou Indevida & 4 & 0 \\
Receita em Branco & 1 & 0 \\
\hline Total de infrações & 24 & 7 \\
\hline Total de responsáveis técnicos & 30 & 30 \\
\hline
\end{tabular}

A principal infração apurada na primeira safra foi a recomendação de agrotóxicos para cultura inexistente, com $79,1 \%$ das infrações. Em algumas situações, a recomendação era para culturas que não existem na região, como tomate e batata, em outras, havia desvio de uso, sendo que o agrotóxico era recomendado para a cultura da soja e o produtor cultivava apenas arroz irrigado. $\mathrm{O}$ uso incorreto dos agrotóxicos, como a não indicação para a cultura alvo, leva a maior exposição e consequente dano à saúde [7]. Muitos produtores afirmaram não conferir o conteúdo da receita agronômica, resultado semelhante ao encontrado em outras pesquisas, onde apenas $23,3 \%$ dos trabalhadores rurais costumam ler os receituários [8]. Em estudos realizados por outros autores, estes descrevem o não uso da receita agronômica por, respectivamente, 64,7\%, $67,2 \%$, e $85,0 \%$ dos entrevistados [3,9,2]. Araújo et al. [10] apontam que apenas $36 \%$ dos agricultores afirmam precisar dessa prescrição para adquirir os agrotóxicos, sendo que $30 \%$ dos trabalhadores sequer a conhecem. Apesar da boa proposta inicial e da fiscalização exercida, ainda hoje não é difícil encontrar em revendas, receituários pré-prontos para os agricultores, quando o mesmo torna-se um "papel a mais" a ser entregue ao produtor no ato da venda [11]. Como exemplo dessa prática, constatou-se na primeira safra um caso de receita assinada em branco na revenda.

Com relação aos 16,6\% de infrações observadas por receita errada, genérica, displicente ou indevida, estão relacionadas à falta de informações, como a área a ser tratada, praga a ser controlada, orientação quanto à obrigatoriedade do uso do EPI e manejo integrado de pragas.

$\mathrm{Na}$ segunda safra, a principal infração foi a recomendação de inseticidas para culturas que ainda não haviam sido implantadas, caracterizando diagnóstico impossível. Foram $71,4 \%$ das infrações por este motivo, todas com indicação de inseticidas. Para Peres et al.[12], tal fato caracteriza a venda antecipada de agrotóxicos e deve-se à pressão exercida pelos setores industrial e comercial de agrotóxicos para um uso predominantemente excessivo, além da despreocupação de parte significativa do setor produtivo com tal situação, as quais são incluídas dentre as prováveis causas de falhas no sistema de manejo de pragas adotado em muitas lavouras brasileiras, podendo isso ser agravado por uma série de determinantes de ordem cultural, social e econômica.

Já dentre as infrações mais comuns nas propriedades, destaca-se a utilização de agrotóxico em desacordo com a receita, o armazenamento irregular, o não fornecimento do EPI, a não destinação correta das embalagens vazias e a não apresentação das receitas agronômicas, as quais, somadas, representam cerca de $84 \%$ das ocorrências em ambos os anos (Tabela 2).

De uma safra para a outra, os resultados nem sempre apontaram para redução de infrações. O único aspecto que apresentou significativa redução foi a utilização de agrotóxico em desacordo com a receita $(p=0,003)$. O armazenamento irregular, a não destinação das embalagens vazias ou seu reuso, o não fornecimento de EPI, além de serem as mais comuns, foram as que se elevaram em termos de frequência, juntamente com a falta de comprovante de devolução das embalagens (Tabela 2).

$\mathrm{O}$ armazenamento torna-se claramente um ponto crítico na região, sendo que na primeira safra foram apontadas $60 \%$ de irregularidades, e na segunda esse valor subiu, atingindo um total de $67,5 \%$. Nas situações irregulares encontradas, existem agricultores que não têm nenhum local isolado para armazenar os agrotóxicos, ficando os mesmos em local de fácil acesso a pessoas e animais domésticos.

A situação do armazenamento é fator preocupante em outras regiões, como observado por Castro et al. [13], onde ao analisarem o uso de agrotóxicos em dois assentamentos no Ceará, verificaram que a maior parte dos entrevistados armazenava os agrotóxicos junto às residências. Em outro trabalho foi identificado que $76 \%$ dos entrevistados armazenam os agrotóxicos em depósitos separados da casa, $21 \%$ de armazenamento em área descoberta e 3\% com armazenamento no interior da residência [7]. No presente estudo não ocorreu armazenamento em residência ou em local descoberto, apenas em depósitos em desacordo com a Norma NBR 9843/13 [6], por diferentes motivos, como distância e material do depósito. 
Tabela 2 - Total de infrações $(\mathrm{n}=80)$ apuradas (com porcentagem de ocorrência) e variação porcentual do antes e depois do início da fiscalização estadual, em cada safra agrícola com relação ao cumprimento da legislação de agrotóxicos e afins na região da Fronteira Oeste do Rio Grande do Sul.

\begin{tabular}{|c|c|c|c|c|}
\hline Infração & $2014 / 15(\%)$ & $2015 / 16(\%)$ & Valor de $p^{* *}$ & Variação $(\%)^{* * *}$ \\
\hline 1- Embaraço à fiscalização & 0 & 0 & -- & 0,0 \\
\hline 2- Utilizar agrotóxico em desacordo com receita & $52(65,0)$ & $30(37,5)$ & 0,0003 & $-27,5$ \\
\hline 3- Armazenamento irregular (depósitos) & $48(60,0)$ & $54(67,5)$ & 0,1619 & 7,5 \\
\hline 4- Não destinar embalagens vazias ou reutilizar & $17(21,3)$ & $24(30,0)$ & 0,1025 & 8,8 \\
\hline 5- Não possuir comprovante de devolução & $2(2,5)$ & $6(7,5)$ & 0,0734 & 5,0 \\
\hline 6- Não fornecer EPI & $20(25,0)$ & $25(31,3)$ & 0,1897 & 6,3 \\
\hline 7- Não usar EPI na aplicação ou preparo da calda* & $4(57,00)$ & $2(28,5)$ & 0,1400 & $-28,5$ \\
\hline 8- Utilizar agrotóxicos sem registro no MAPA & 0,0 & $2(2,5)$ & -- & 2,5 \\
\hline 9- Utilizar agrotóxicos com restrição de uso no RS & $8(10,0)$ & $4(5,0)$ & 0,1150 & $-5,0$ \\
\hline 10- Não entregar documentação & $5(6,3)$ & $6(7,5)$ & 0,3774 & 1,3 \\
\hline 11- Não apresentar receitas agronômicas & $15(18,8)$ & $12(15,0)$ & 0,2633 & $-3,8$ \\
\hline 12- Causar danos ao meio ambiente & $1(1,3)$ & $1(1,3)$ & 0,5000 & 0,0 \\
\hline 13- Dar outra destinação aos agrotóxicos apreendidos & 0,0 & $1(1,3)$ & -- & 1,3 \\
\hline 14- Desobediência às determinações da SEAPI & 0 & $6(7,5)$ & -- & 7,5 \\
\hline Total & 172 & 173 & -- & -- \\
\hline
\end{tabular}

* Neste item foram realizadas sete abordagens $(\mathrm{n}=7)$;

** Valor de p para o teste Binomial, entre as safras avaliadas

*** Variação percentual entre antes e após a atividade da fiscalização estadual.

Em um estudo realizado por Bigatão [14], 53\% dos entrevistados armazenavam agrotóxicos em local exclusivo para este fim, $44,8 \%$ armazenavam junto a outros produtos e $0,7 \%$ na garagem de sua casa. Dados semelhantes foram verificados neste trabalho, onde existem diversos agricultores que armazenam agrotóxicos junto a rações, sementes, adubos e em locais com fluxo de pessoas como a oficina. Sobre o armazenamento junto a outros produtos, Boziki et al.[15], descreveram que 25\% dos entrevistados responderam que armazenavam os agrotóxicos em galpões, sendo que os mesmos estavam junto a alimentos e rações de animais, corroborando com os dados obtidos nas propriedades rurais avaliadas na Fronteira Oeste do RS.

Os artigos que tratam deste assunto não trazem informações sobre as condições estruturais dos depósitos, apenas se os mesmos ficam trancados e se existem construções independentes das moradias. Assim, não é possível avaliar se o armazenamento é seguro e está de acordo com o exigido pela legislação, pois não existem informações sobre as condições do depósito, como material utilizado, fiações, distâncias de residências e fontes de água [16].

$\mathrm{Na}$ região na qual houve a coleta de dados, muitos agricultores alegam não possuir depósito, em virtude de não estocarem agrotóxicos, sendo que os mesmos afirmam que são informados se há presença de alguma praga provocando danos à lavoura pelo técnico agrícola ou agrônomo, geralmente funcionário de uma empresa de comercialização de agrotóxicos. Esse agente comunica a revenda, que envia os agrotóxicos no momento da aplicação, sendo que a equipe da aviação agrícola realiza a aplicação (sistema de aplicação predominante na região devido às lavouras de arroz irrigado), recolhendo as embalagens vazias e devolvendo ao posto.

Na prática, regularmente observa-se agrotóxico estocado de forma inadequada na propriedade rural, sendo que as misturas de agrotóxicos que não são utilizadas, por exemplo, costumeiramente são armazenadas em embalagens de 20 litros e dispostas em algum local sem as mínimas condições. Segundo Veiga et al. [17], os danos causados pelos agrotóxicos podem 
ocorrer na produção, transporte, armazenamento, manipulação e até no descarte das embalagens vazias, sendo assim, o armazenamento deve ser motivo de maior atenção por parte dos agricultores.

Os valores de infrações a respeito do armazenamento de embalagens vazias de agrotóxicos foram elevados. Essa situação, no entanto, ocorre em outras regiões do país, apesar de no presente trabalho não terem sido medidas tais proporções. Leite \& Torres [18], avaliando a proporção de armazenamentos irregulares no Rio Grande do Norte, encontraram $68 \%$ de armazenamento ao ar livre, varanda ou campo. Castro \& Confalonieri [2], em um trabalho semelhante ao anterior, realizado no Estado do Rio de Janeiro, assinalaram que 47,5\% armazenavam em local adequado, $22,5 \%$ junto a outros materiais, $14 \%$ em locais ao ar livre e $5 \%$ na própria residência.

A destinação de embalagens vazias de agrotóxicos foi outro ponto avaliado, apresentando uma elevação considerável de $8,7 \%$ em relação às irregularidades. Desde junho de 2002, a devolução é obrigatória e, segundo Sato et al. [19], a devolução das embalagens vazias é responsabilidade do usuário, comerciante e fabricante. Na primeira safra avaliada, de 80 agricultores fiscalizados, $21,3 \%$ não destinaram adequadamente as embalagens vazias de agrotóxicos, enquanto que na safra seguinte este valor subiu $30 \%$.

O aumento observado referente ao descarte incorreto das embalagens deve-se em parte a situações nas quais as embalagens encontravam-se espalhadas pela propriedade e a céu aberto, sem proteção, mas principalmente, por reutilização das mesmas. Bohner et al. [8] encontraram resultados de $83 \%$ de agricultores devolvendo embalagens no local indicado na nota fiscal, semelhante ao encontrado no estudo que apontou 78,7\% no primeiro ano e $70 \%$ no segundo. Segundo Fonseca et al. [20] a devolução de embalagens é o único comportamento adequado com relação às normas de proteção. Já Preza \& Augusto [7] observaram que $62 \%$ dos agricultores efetuava a devolução das embalagens para as revendas, porém $31 \%$ destes ainda faziam o descarte de embalagens no campo.

Conforme descrito por Boas \& Bedor [21], muitos danos ao ambiente se devem aos conhecimentos precários de agricultores sobre os cuidados na aplicação de agrotóxicos e as formas corretas de descarte de embalagens vazias. Apesar da obrigatoriedade da realização da tríplice lavagem para embalagens rígidas que contiverem formulações miscíveis ou dispersíveis em água, são encontradas com frequência embalagens com resíduos de agrotóxicos. Segundo Reinato et al. [11], em situações de campo, não há garantida da realização do procedimento correto de lavagem de embalagens vazias.

Com relação à infração de não fornecer o Equipamento de Proteção Individual (EPI), houve aumento de $25 \%$ para $31,3 \%$ no número de empregadores rurais que não o forneceram aos empregados. Essa elevação pode ser explicada pelas características das propriedades fiscalizadas, já que a presença do EPI é menos recorrente em propriedades familiares com poucos funcionários, característica mais presente na segunda safra avaliada.

Importante ressaltar que mesmo tendo o EPI na propriedade, raramente o mesmo é utilizado. No caso de trabalhadores rurais, além de não compreenderem o processo de contaminação por agrotóxicos, desconhecem ou desconsideram a necessidade da utilização de alguns equipamentos de proteção individual [22]

Em relação à não apresentação do comprovante de devolução de embalagens vazias, na primeira safra $2,5 \%$ dos agricultores não apresentaram o comprovante, na segunda foram $7,5 \%$, variação positiva de $5 \%$. A não apresentação do comprovante não indica diretamente que os agricultores não efetuaram a devolução, pois na maioria dos casos, os mesmos não apresentaram nenhuma documentação solicitada, em virtude de estarem com diversas irregularidades relacionadas à legislação de agrotóxicos e optaram por não apresentar os documentos solicitados pela fiscalização.

Apesar de o Brasil ser considerado uma referência mundial com relação à devolução de embalagens vazias de agrotóxicos, ainda há muito descontrole nesse processo. Nas duas safras avaliadas, dois postos apresentaram irregularidades, um estava superlotado, com total descontrole de devoluções, o outro foi fechado em novembro de 2014, permanecendo assim durante toda a safra de verão. Para Reinato et al. [11] existe necessidade de se intensificar a fiscalização em todo o processo de devolução de embalagens vazias de agrotóxicos, pois é comum encontrar agricultores que não devolvem embalagens e postos de recebimento inadequados.

Outras infrações apresentaram valores superiores após o trabalho de conscientização, porém não foram tão importantes como os mencionados anteriormente em função de sua baixa ocorrência. A infração de utilizar agrotóxicos ilegais ou banidos, ou seja, não registrados no Ministério da Agricultura, Pecuária e Abastecimento (MAPA) não ocorreu na primeira safra, enquanto que na seguinte foram notificadas duas ocorrências. Anota-se que os agrotóxicos encontrados nas propriedades tinham origem do Uruguai e Argentina e isso se justifica, principalmente, em função da localização geográfica da região, fronteira com esses dois Países, facilitando assim a entrada de agrotóxicos contrabandeados. Esse fato se agrava quando se lança mão do estudo de Bedor et al. [3], no qual $70 \%$ dos agricultores não sabiam diferenciar um agrotóxico contrabandeado de um agrotóxico legal.

A infração de não entregar documentação (receitas agronômicas, comprovantes de devolução de embalagens e notas fiscais) ocorreu em $6,3 \%$ das propriedades rurais na safra $2014 / 15$ e em $7,5 \%$ na safra $2015 / 16$. 
Houve apenas uma ocorrência na safra 2015/16 referente à infração de dar outra destinação a agrotóxico e afins apreendidos ou com uso suspenso pela fiscalização. O produtor fiscalizado deveria ter efetuado a devolução ao fabricante dos agrotóxicos com prazo de validade vencido, no entanto, ele foi novamente fiscalizado, não comprovando a devolução dos mesmos, bem como a inexistência dos produtos no estoque, passando o percentual de $0 \%$ a $1,3 \%$.

A última infração avaliada que apresentou elevação refere-se à desobediência às determinações do órgão competente. Em algumas situações é concedido um prazo ao produtor para que regularize uma situação ou então alguma documentação é solicitada a fim de apurar infrações relacionadas à legislação de agrotóxicos. Na primeira safra avaliada, não ocorreu esta infração, até porque não havia solicitações anteriores pendentes, já na segunda safra, a infração ocorreu em 7,5\% das propriedades fiscalizadas.

Causar danos ao meio ambiente foi a infração que manteve o mesmo nível de ocorrência em ambas as safras, verificada em uma propriedade fiscalizada. Na safra 2014/15 um produtor fez o descarte de embalagens vazias no campo, ao lado de um córrego que conduzia os resíduos das embalagens para uma barragem. Na safra seguinte, houve descarte de embalagens vazias e caixas de agrotóxicos em um buraco no solo, juntamente com o lixo doméstico, onde as mesmas seriam queimadas e posteriormente enterradas. Percebe-se, com isso, que a preocupação deve estar em todas as etapas, uso, manejo e descarte das embalagens vazias, pois, segundo Gonçalves-Dias [23], as embalagens são um dos principais pontos de discussão das políticas públicas.

Não houve registro da infração de embaraço à fiscalização, situação que ocorre quando a fiscalização não pode ser efetuada em função de não ser possibilitado o acesso à propriedade ou a alguma parte da mesma, como, por exemplo, ao depósito. Todos os agricultores fiscalizados foram solícitos e deram total acesso para que o trabalho fosse realizado, sem qualquer tipo de limitação ou impedimento.

A utilização de agrotóxicos em desacordo com a receita, o não uso de EPI na aplicação ou preparo da calda, o uso de agrotóxicos com restrição no RS e a não apresentação das receitas agronômicas tiveram queda nos percentuais. Destaca-se como ponto positivo da atuação da fiscalização o fato de que o uso de agrotóxico em desacordo com receita apresentou uma queda de $27,5 \%$. Isso se deve ao maior controle dos agricultores e dos responsáveis técnicos na emissão das receitas agronômicas, precavendo-se de possíveis autuações. Esse tipo de infração normalmente ocorre quando o agrotóxico é utilizado em cultura diferente do que está na receita agronômica e bula do produto ou é aplicado de forma irregular, para a qual não é registrado.

Nesse caso, a redução pode ser explicada pelos comerciantes, que diante da presença constante da fiscalização, reduziram os agrotóxicos recomendados para a cultura da soja que eram utilizados em arroz. Essa situação era bastante comum na região e, mesmo na safra 2015/16, foi o que mais levou a infrações por uso em desacordo com a receita, salvo uma exceção na qual o agrotóxico era registrado apenas para a cultura da canade-açúcar.

Diferentes estudos apontam para dificuldade de entendimento dos rótulos e bulas dos agrotóxicos. Corrobora nesse sentido, o estudo realizado por Polastro [24], onde ele menciona que a rotulagem dos produtos apresenta orientações técnicas que inviabilizam o entendimento por parte dos usuários. Sendo assim, os trabalhadores rurais necessitam de orientação adequada com relação à linguagem utilizada nas instruções dos produtos [18, 12]. Siqueira \& Kruse [25] definem a linguagem pouco acessível como um entrave ao entendimento dos usuários, já Yamashita \& Santos [26], além da linguagem, citam que o tamanho reduzido das letras dos rótulos desestimula o usuário à leitura.

A não utilização do EPI durante a aplicação ou preparo da calda apresentou redução de $57 \%$ para $28,5 \%$, em um total de sete abordagens. O número reduzido de inspeções, no entanto, não permitiu a detecção de significância estatística para este dado (Tabela 2), mesmo que essa redução tenha sido de $28,5 \%$ entre a primeira e segunda safra em termos absolutos. É importante salientar que são poucas as ações em que a fiscalização é realizada no momento da aplicação do agrotóxico, ocorrendo principalmente quando há aplicação aérea e a abordagem é realizada diretamente na pista.

Em seu trabalho, Recena \& Caldas [27] encontraram $17,2 \%$ de trabalhadores que usam o EPI completo e $27,6 \%$ que não usam proteção alguma. Ainda, nesse mesmo estudo, $93 \%$ dos entrevistados eram aplicadores e preparadores dos agrotóxicos, situação similar à encontrada na Fronteira Oeste do Rio Grande do Sul. Polastro [24] chegou ao valor de 74,6\% de trabalhadores que usam EPI, pois quando questionados sobre o EPI, os trabalhadores e aplicadores afirmam utilizar, porém na prática isso não ocorre, de forma semelhante ao descrito por Boziki et al. [15].

Em um estudo conduzido por Bedor et al.[3] estes concluíram que $83,7 \%$ dos entrevistados utilizam algum tipo de equipamento de proteção individual enquanto $16,3 \%$ não utilizam nenhum tipo de equipamento. Castro et al. [13] de acordo com o relato dos entrevistados, chegaram ao valor de $50 \%$ de utilização de bota ou chapéu, confirmando que a utilização do EPI em muitos casos é parcial, situação verificada no presente estudo. Quando questionados sobre não usar o EPI, os trabalhadores rurais afirmam que o calor e o desconforto do equipamento levam a não utilização. Esta informação está de acordo com os estudos de Jacobson et al.[28]; Schmidt \& Godinho [29]; Alves et al.[30]; Marques et al.[31]; Gonçalves et al.[9] e Silva et al.[32]. 
Na primeira safra de fiscalização houve um total de $10 \%$ de irregularidade com uso de agrotóxicos não cadastrados na FEPAM ou com restrição de uso no Rio Grande do Sul, já na segunda safra houve apenas 5\%. A legislação do Rio Grande do Sul é mais restritiva com relação à liberação de comercialização e uso de agrotóxicos, pois alguns produtos que são liberados para uso no Brasil, estão proibidos no Estado pelo órgão responsável, a FEPAM.

A não apresentação das receitas agronômicas dos agrotóxicos adquiridos apresentou redução de 3,8\% entre as safras. Em algumas situações o produtor não apresentou as receitas por receio, já que o agrotóxico não era registrado para a sua cultura, em outras o produtor não tinha a receita, pois o produto foi adquirido de forma ilegal, sem receita e nota fiscal, por estar com cadastro indeferido junto à FEPAM.

Diante dos resultados obtidos, algumas considerações podem ser feitas. O uso é excessivo e mesmo com a presença da fiscalização, infrações ocorrem em grande número. Alguns autores, como Castro \& Confalonieri [2] afirmam que parte dos agricultores está ciente dos riscos da utilização de agrotóxicos, porém continuam fazendo uso dos mesmos por necessidade de sobrevivência financeira, uma vez que dependem do cultivo agrícola. Mesmo diante de todos os riscos que envolvem os agrotóxicos, o uso é constante e está longe de ser eliminado [20]. A exposição dos agricultores aos agrotóxicos, segundo Akatar et al. [33], está diretamente relacionada a problemas de saúde, podendo-se mencionar distúrbios hormonais, déficit de inteligência, anormalidades reprodutivas e, principalmente câncer. Além disso, o uso indiscriminado de agrotóxicos está causando problemas adversos aos ecossistemas, afetando diversas espécies aquáticas e terrestres Jayaraj et al. [34].

Durante a coleta de dados, a partir das abordagens feitas aos agricultores, tanto aos funcionários como aos proprietários das áreas de cultivo, percebe-se que há falta de informação. Segundo Pires et al. [35] há necessidade de um tratamento educativo adaptado aos aspectos regionais, locais, culturais e ideológicos da população. A explicação mais usual sobre o descontrole no uso de agrotóxicos é a falta de conhecimento e de instruções sobre como proceder [36]. O papel do governo, nesse contexto, é de extrema importância, pois as condições educacionais inviabilizam a proteção ao trabalhador, além de não contarem com um serviço de saúde acessível e que faça o papel de agente orientador ao usuário [35,37,12].

\section{Conclusões}

As infrações mais comuns foram a utilização de agrotóxico em desacordo com a receita, o armazenamento irregular, o não fornecimento do EPI, a não destinação correta das embalagens vazias e a não apresentação das receitas agronômicas. Também, a presença da fiscalização auxiliou diretamente na utilização de agrotóxicos em conformidade com a receita. Desse modo, a redução dos riscos de contaminação ambiental pode ser obtida com a maior rigidez das ações oficiais de fiscalização, resultando na melhoria da qualidade de vida dos trabalhadores rurais.

\section{Agradecimentos}

Universidade Federal do Pampa (Unipampa) e a Secretaria da Agricultura Pecuária e Irrigação, Inspetoria de Defesa Agropecuária de Itaqui.

\section{INSPECTIONS ACTIONS AND APPROPRIATE USE OF PESTICIDES BY FARMERS IN WEST FRONTIER REGION, RIO GRANDE DO SUL}

ABSTRACT: The lack of supervision on the use of pesticides by farmers is an aggravating factor for legislation compliance. The objective of this study was to evaluate the validity of the inspections actions in compliance with the law regarding the use of pesticides by farmers on the west border of Rio Grande do Sul, Brazil, and its consequences to health and the environment. We inspected 80 farms in two harvests before and after the official state guidelines inspection. The pesticide deposits were evaluated, along with availability and use of personal protective equipment (PPE), agronomical prescription, return of empty pesticide containers and use of pesticides, according to the rules and legal procedures. The evaluations were grouped into 14 possible violations of pesticide laws. There was an increase in eight types of violations and four showed a reduction. The most common irregularities were the use of pesticides in disagreement with the agronomic prescription, irregular storage, not providing PPE, incorrect disposal of empty containers and the nonpresentation of agronomic prescription. The presence of surveillance assisted directly with the use of pesticides in accordance with the agronomic prescription.

Keywords: agronomic prescription; law of pesticides; agricultural inspection; health risk.

\section{Referências}

[1] CARNEIRO, F. F. et al. Organizadores. Dossiê Abrasco: um alerta sobre os impactos dos agrotóxicos na saúde $1^{\text {a }}$ Parte. Rio de Janeiro: Associação Brasileira de Saúde Coletiva. 640 p. 2012.

[2] CASTRO, J. S. M.; CONFALONIERI, U. Uso de agrotóxicos no Município de Cachoeiras de Macacu (RJ). Ciência \& Saúde Coletiva, Rio de Janeiro, v. 10, n. 2, p. 473-482, 2005. 
[3] BEDOR, C.N.G. et al. Vulnerabilidades e situações de riscos relacionados ao uso de agrotóxicos na fruticultura irrigada. Revista Brasileira de Epidemiologia, São Paulo, v. 12, n. 1, p. 39-49, 2009.

[4] SOBREIRA, A. E. G.; ADISSI, P. J. Agrotóxicos: falsas premissas e debates. Ciência \& Saúde Coletiva, Rio de Janeiro, v. 8, n. 4, p. 985-990, 2003.

[5] ANDEF. Associação Nacional de Defesa Vegetal. Posicionamento da indústria de defensivos agrícolas sobre a importação direta dos produtos pelo agricultor. Defesa Agrícola , ano I, n. 2 , set. 2005

[6] ABNT-ASSOCIAÇÃO BRASILEIRA DE NORMAS TÉCNICAS. NBR 9843-3: Armazenamento em propriedades rurais. Rio de Janeiro, 2013. 4 p.

[7] PREZA, D. de L. C.; AUGUSTO, L. G. da S. Vulnerabilidades de trabalhadores rurais frente ao uso de agrotóxicos na produção de hortaliças em região do Nordeste do Brasil. Revista Brasileira de Saúde Ocupacional, São Paulo, v. 37, n. 125, p. 89-98, 2012.

[8] BOHNER, T.O.L. et al. O impacto ambiental do uso de agrotóxicos no meio ambiente e na saúde dos trabalhadores rurais. Revista Eletrônica do Curso de Direito da UFSM, Santa Maria, v. 8, p. 329-341, 2013.

[9] GONÇALVES, G.M.S. et al. Uso de agrotóxicos e a relação com a saúde na etnia Xukuru do Ororubá, Pernambuco, Brasil. Saúde e Sociedade, São Paulo, v. 21, n. 4, p. 1001-1012, 2012.

[10] ARAUJO A.C. et al. Impacto dos praguicidas na saúde: estudo da cultura de tomate. Revista Saúde Pública, São Paulo, v 34, n.3, p. 309-313, 2000.

[11] REINATO, R.A. et al. A situação atual das embalagens vazias de agrotóxicos no Brasil. Engenharia Ambiental, Campina Grande, v.9, n.4, p.79-94, 2012.

[12] PERES, F. et al. Desafios ao estudo da contaminação humana e ambiental por agrotóxicos. Ciência \& Saúde Coletiva, Rio de Janeiro, v. 10, n. supl. 0, p. $27-37,2005$

[13] CASTRO, M.G.G.M. et al. Uso de agrotóxicos em assentamentos de reforma agrária no Município de Russas (Ceará, Brasil): um estudo de caso. Epidemiologia e Serviços de Saúde, Brasília, v. 20, n. 2, p. 245-254, 2011.

[14] BIGATÃO, D. A. R. Cuidados e destinação final de embalagens, na utilização de agrotóxicos por produtores rurais no município de Itaporã - MS. 2009. 85p. Dissertação de Mestrado em Ciências da Saúde pela Universidade de Brasília, Brasília.

[15] BOZIKI, D. et al. Situação atual da utilização de agrotóxicos e destinação de embalagens na área de proteção ambiental estadual Rota do Sol, Rio Grande do Sul Brasil. Revista Vitas, Rio de Janeiro, v. 1, n. 1, p. 1-15, 2011

[16] ABREU, P. H. B. de; ALONZO, H. G. A. Trabalho rural e riscos à saúde: uma revisão sobre o "uso seguro" de agrotóxicos no Brasil. Ciência \&Saúde Coletiva, Rio de Janeiro, v. 19, n. 10, p. 4197- 4208, 2014.

[17] VEIGA, M. M. et al. Eficiência da intervenção legal na destinação final de embalagens vazias de agrotóxicos. In: Associação Brasileira de Engenharia Sanitária e Ambiental. Saneamento Ambiental Brasileiro: Utopia ou Realidade?. Rio de Janeiro: ABES, p. 1- 6, 2005.

[18] LEITE, K. da C.; TORRES, M. B. R. O uso de agrotóxicos pelos trabalhadores rurais do assentamento catingueira Baraúna-RN. Revista verde de agroecologia e desenvolvimento sustentável, Pombal, v. 3, n. 4, p. 06-28, 2008.

[19] SATO, G.S. et al. Práticas operacionais da logística de embalagens de agrotóxicos no Brasil. Revista de Gestão Integrada em Saúde do Trabalho e Meio Ambiente, São Paulo, v. 1, n. 1, p. 10-21, 2006.

[20] FONSECA, M.D.G.U. et al. Percepção de risco: maneiras de pensar e agir no manejo de agrotóxicos. Ciência \& Saúde Coletiva, Rio de Janeiro, v. 12, n.1, p. 39-50, 2007.
[21] BOAS, J. M. V.; BEDOR, C. N. G. Prevenção das intoxicações por agrotóxico no Sub médio do Vale do São Francisco junto a trabalhadores rurais. Extramuros - Revista de Extensão da Univasf, Petrolina, v. 1, n. 1, p. 70-80, 2013.

[22] STOPPELli, I. M. de B. S.; MAGALHAES, C. P. Saúde e segurança alimentar: a questão dos agrotóxicos. Ciência \& Saúde Coletiva, Rio de Janeiro, v. 10, n. supl. 0, p. 91-100, 2005

[23] GONÇALVES-DIAS, S. L. F. Há vida após a morte: um (Re) pensar estratégico para o fim da vida das embalagens. Gestão \& Produção, São Carlos, v. 13, n. 3, p. 463-474, 2006.

[24] POLASTRO, D. Estudo dos casos de intoxicação ocasionados pelo uso de agrotóxicos no Estado do Paraná, durante o período de 1993 a 2000. 2005. 125p Dissertação de Mestrado em Ecologia de Agroecossistemas pela Universidade de São Paulo.

[25] SIQUEIRA, S.; KRUSE, M. H. L. Agrotóxicos e a saúde humana: contribuição dos profissionais do campo da saúde. Revista da Escola de Enfermagem, São Paulo, v. 42, n. 3, p. 584-90, 2008

[26] YAMASHITA, M. G. N.; SANTOS, J. E. G. Rótulos e bulas de agrotóxicos: parâmetros de legibilidade tipográfica. In: PASCHOARELLI, L.C.; MENEZES, M.S. Design e ergonomia: aspectos tecnológicos. São Paulo: Editora UNESP, 2009. Cap. 9, p. 197-222, 2009

[27] RECENA, M. C. P.; CALDAS, E. D. Percepção de risco, atitudes e práticas no uso de agrotóxicos entre agricultores de Culturama, MS. Revista de Saúde Pública, São Paulo, v. 42, n. 2, p. 294-301, 2008.

[28] JACOBSON, L.S.V.et al. Comunidade pomenara e uso de agrotóxicos: uma realidade pouco conhecida. Ciência \& Saúde Coletiva, Rio de Janeiro, v. 14, n. 6, p. 2239-2249, 2009.

[29] SCHMIDT, M. L. G.; GODINHO, P. H. Um breve estudo acerca do cotidiano do trabalho de produtores rurais: intoxicações por agrotóxicos e subnotificação. Revista Brasileira de Saúde Ocupacional, São Paulo, v. 31, n. 113, p. 27-40, 2006.

[30] ALVES, S. M. F. et al. Análise de correspondência como instrumento para descrição do perfil do trabalhador da cultura de tomate de mesa em Goiás. Ciência Rural, Santa Maria, v. 39, n. 7, p. 2042-2049, 2009

[31] MARQUES, C.R.G. et al. Diagnóstico do conhecimento de informações básicas para o uso de agrotóxicos por produtores de hortaliças da Região de Londrina. Semina, Londrina, v. 31, n. 3, p. 547-556, 2010.

[32] SILVA, J.P.L. et al. Panorama da vulnerabilidade da saúde do agricultor familiar de São José de Princesa/PB. Revista Brasileira de Ciência da Saúde, João Pessoa, v. 17, n. 1, p. 29-38, 2013

[33] AKATAR, M. W. et al. Impact of pesticides use in agriculture: their benefits and hazards. Interdisciplinary Toxicology, Poland, v. 02, n. 1, p. 1-12, 2009.

[34] JAYARAJ. R. et al. Organochlorine pesticides, their toxic effects on living organisms and their fate in the environment. Interdisciplinary Toxicology, Poland, v. 09, n. 3, p. 90-100, 2016

[35] PIRES, D.X. et al. Uso de agrotóxicos e suicídios no Estado do Mato Grosso do Sul, Brasil. Cadernos de Saúde Pública, Rio de Janeiro, v. 21, n. 2, p. 598-605, 2005 .

[36] SEGURA-MUÑOZ, S.I. et al. Condições de saúde ambiental e infância: análise das intoxicações por agentes químicos no Brasil. O Mundo da Saúde, São Paulo, v. 29, n. 2, p. 199-206, 2005.

[37] BRITO, P. F. de. et al. Trabalho e exposição aos agrotóxicos em uma pequena comunidade agrícola no município do Rio de Janeiro. Cadernos de Saúde Coletiva, Rio de Janeiro, v. 14, n. 3, p. 531-548, 2006. 